\title{
Prediction of Anxiety and Behavioural Disturbances by Temperamental Characters in Children
}

\author{
Peyman Hashemian \\ Psychiatry and Behavioral Sciences Research Center, Faculty of Medicine, Mashhad University of \\ Medical Sciences, Ibn-e-Sina Hospital, Mashhad, Iran \\ Email: hashemianp@mums.ac.ir
}

Received 19 November 2015; accepted 19 January 2016; published 22 January 2016

Copyright (C) 2016 by authors and Scientific Research Publishing Inc.

This work is licensed under the Creative Commons Attribution International License (CC BY). http://creativecommons.org/licenses/by/4.0/

(c) (i) Open Access

\begin{abstract}
Background: Temperament is a predictive factor of child behaviour. Thomas and Chess evaluated relationship of temperamental factor with behavioural disturbance in social milo. Method: In this study, 500 children between 4 to 10 years old, who have been admitted for their behavioural disturbance and anxiety to Dr-Sheikh Children Hospital in Mashhad, Iran, have been chosen. The parents fill Malhotra questionnaire and Conner's questionnaire. Then subscales of questionnaires are compared together. Result: Power and energy (activity) are the only factors which are in relation with conduct behaviour, impulsivity, hyperactivity and anxiety. Conclusion: Among temperament factor only power and energy (activity) have relation with conduct behaviour, impulsivity, hyperactivity and anxiety. Focus of attention (distractibility) is associated with hyperactivity. Sociability has no relationship with hyperactivity.
\end{abstract}

\section{Keywords}

Temperamental Characters, Behavioural Disturbances, Anxiety, Children

\section{Introduction}

Temperament is a predictive factor for child behaviour. It is an essential agent for self-regulation and a part of future personality formation.

Berdan L.E. and colleagues in 2008 studied the relationship of temperament with behavioural disturbance and social growth [1]. Goodnight J.A. and his team in 2007 found the relationship between difficult temperaments with behavioural disturbance as well as sleep disturbance [2]. Eisenberg N. and crew in 2009 evaluated the im- 
pact of negative emotion on behavioural disturbance [3].

Bates J.E. and colleagues studied the type of temperament and parents on future behavioural disturbance [4]. Researches of De Pauw and Mervielde [5] as well as Bucky and Edwards [6] showed the effectiveness of temperamental character on future personality and psychiatric state. Chess and Thomas and their team evaluated temperamental characters and environmental effect on future behavioural disturbance [7]. Miti found the efficacy of temperamental and environmental factors on personality growth [8]. Mc Inerny and Chamberl in conducted a study on the effect of temperamental characters on future behavioural disturbances [9]. Camerone valuated the influence of temperamental characters of child and parents on future behavioural disturbances [10].

The Malhotra temperament measurement schedule assesses temperament of children [11]. The test-retest reliability of this schedule is 0.83 to 0.94 with satisfactory factorial and construct validity [11]. The Conners' Parent Rating Scale is used to assess childhood behavioural disturbances [12]. Subscales of Conners' Parent Rating Scale are conduct symptom, impulsivity, anxiety, and hyperactivity [12]. Temperamental characters include power and energy (activity), focus of attention (distractibility), excitability, sociability, and regularity [11]. Sociability consists of approaching behaviour and adaptability and threshold of response [11]. Excitability consists of mood state and persistency [11]. Power and energy (activity) consist of activity level and intensity of response [11].

\section{Method}

In this study, 500 children between 4 - 10 years old were selected with the average age of 7.09 years. 304 of which were boys and 196 were girls. These children were referred to sheikh children hospital in Mashhad, Iran in 2011 for their symptoms of behavioural disturbance and anxiety. They had no medical disorder. Their behavioural symptoms included hyperactivity, impulsivity (aggression) and conduct disorder.

Informed consents were taken from their parents. Parents filled out Malhotra temperament measurement schedule [11] and Conners' Parent Rating Scale [12]. Subscales of Conner's Parent Rating Scale (including conduct symptom, impulsivity, anxiety, and hyperactivity) were compared with temperamental characters (including power and energy (activity), focus of attention (distractibility), excitability, sociability, regularity).

Mann-Whitney, two-tailed t-tests were used to compare the two questionnaires, with SPSS software, version 20.

\section{Result}

In this study 500 children were selected, 304 of which were boys (60.8\%) and 196 were girls (39.2\%).

Table 1 shows that among temperamental characters, only power and energy (activity) had been associated with conduct symptom. This means the more active the child, the more conduct symptom he/she has. $(P$-value $=$ 0.001).

As can be seen in Table 2, among temperamental characters, only power and energy (activity) and focus of attention (distractibility) were related with impulsivity. This shows the more active and distracted the child, the more impulsive behaviour he/she might be ( $P$-value $=0.000$ and 0.018$)$.

As shown in Table 3, among temperamental character only power and energy (activity) was related with symptoms of anxiety. The more active the child, the more anxious he/she might be $(P$-value $=0.004)$.

Table 4 shows that among temperamental character only sociability had no relationship with hyperactivity but other characters including excitability, energy, focus of attention (distractibility), regularity had relationship with hyperactivity. It means the more irregular, distractive, active and excited the child, the more hyperactive

Table 1. Relationship between conduct symptom and temperamental characters.

\begin{tabular}{cccccc}
\hline & Regularity & Focus of Attention & Energy & Excitability & Sociability \\
\hline Asymp. Sig. (2-tailed) & 0.034 & 0.167 & 0.001 & 0.523 & 0.310 \\
\hline
\end{tabular}

Table 2. Relationship between impulsivity and temperamental characters.

\begin{tabular}{cccccc}
\hline & Regularity & Focus of Attention & Energy & Excitability & Sociability \\
\hline Asymp. Sig. (2-tailed) & 0.065 & 0.018 & 0.000 & 0.091 & 0.276 \\
\hline
\end{tabular}


Table 3. Relationship between anxiety and temperamental characters.

\begin{tabular}{lccccc}
\hline & Regularity & Focus of Attention & Energy & Excitability & Sociability \\
\hline Asymp. Sig. (2-tailed) & 0.108 & 0.726 & 0.004 & 0.891 & 0.315 \\
\hline
\end{tabular}

Table 4. Relationship between hyperactivity and temperamental characters.

\begin{tabular}{lccccc}
\hline & Regularity & Focus of Attention & Energy & Excitability & Sociability \\
\hline Asymp. Sig. (2-tailed) & 0.010 & 0.000 & 0.000 & 0.001 & 0.770 \\
\hline
\end{tabular}

he/she can be $(P$-value $=0.010,0.000,0.000,0.001)$.

\section{Discussion}

In this study, relationship between temperamental characters and behavioural disturbances and anxiety were compared. Temperamental characters include regularity, focus of attention, power and energy (activity), excitability and sociability. Behavioural disturbances include conduct, impulsivity, hyperactivity symptoms.

We found out that among temperamental factors, only power and energy (activity) had significant relation with conduct behaviour, impulsivity, hyperactivity and anxiety. Regularity and focus of attention (distractibility) and excitability and energy had significant relationship with hyperactivity.

Sociability had no relationship with hyperactivity. Regularity and focus of attention (distractibility) and excitability and sociability had no relation with conduct symptoms. Regularity and excitability and sociability had no relation with impulsivity symptoms. Regularity and focus of attention (distractibility) and excitability and sociability had no relationship with anxiety. This study is compatible with study of Burdan [1], Gunter [13], Rothbart [14], Foley [15], Harris [16], and Lonigan [17]. The above references show that temperament affects behavioural disturbances (externalizing symptoms), emotion and socializing behaviour.

\section{Conclusions}

Among all temperamental characters, high power and energy, excitability, distractibility and irregularity can be predictive as below:

1-high power and energy (high activity) in children can be predictive of anxiety and behavioural disturbance such as hyperactivity, conduct.

2-excitability and low focus of attention (distractibility) and irregularity can be predictive of hyperactivity.

\section{Limitation and Recommendation}

This study was performed in one center. Multi-center study is suggested.

The present study can be used as a preliminary study for a future prospective cohort study for evaluation of correlation of temperamental characters with emotional and behavioural disturbances.

\section{References}

[1] Berdan, L.E., Keane, S.P. and Calkins, S.D. (2008) Temperament and Externalizing Behavior: Social Preference and Perceived Acceptance as Protective Factors. Developmental Psychology, 44, 957-968. http://dx.doi.org/10.1037/0012-1649.44.4.957

[2] Goodnight, J.A., Bates, J.E., Staples, A.D., Pettit, G.S. and Dodge, K.A. (2007) Temperamental Resistance to Control Increases the Association between Sleep Problems and Externalizing Behavior Development. Journal of Family Psychology, 21, 39-48. http://dx.doi.org/10.1037/0893-3200.21.1.39

[3] Eisenberg, N., Valiente, C., Spinrad, T.L., Cumberland, A., Liew, J., Reiser, M., Zhou, Q. and Losoya, S.H. (2009) Longitudinal Relations of Children's Effortful Control, Impulsivity, and Negative Emotionality to Their Externalizing, Internalizing, and Co-Occurring Behavior Problems. Developmental Psychology, 45, 988-1008. http://dx.doi.org/10.1037/a0016213

[4] Bates, J.E., Pettit, G.S., Dodge, K.A. and Ridge, B. (1998) Temperamental Resistance to Control and Restrictive Parenting in the Development of Externalizing Behavior. Developmental Psychology, 34, 982-995.

http://dx.doi.org/10.1037/0012-1649.34.5.982 
[5] De Pauw, S.S. and Mervielde, I. (2010) Temperament, Personality and Developmental Psychopathology: A Review Based on the Conceptual Dimensions Underlying Childhood Traits. Child Psychiatry \& Human Development, 41, 313329.

[6] Bucky, S.F. and Edwards, D. (1974) The Recruit Temperament Survey (RTS) as It Discriminates between Psychoses, Neuroses, and Personality Disorders. Journal of Clinical Psychology, 30, 195-199. http://dx.doi.org/10.1002/1097-4679(197404)30:2<195::AID-JCLP2270300223>3.0.CO;2-2

[7] Chess, S., Thomas, A., Rutter, M., Birch, H.G. and Birch, H. (1963) Interaction of Temperament and Environment in the Production of Behavioral Disturbances in Children. American Journal of Psychiatry, 120, 142-148. http://dx.doi.org/10.1176/ajp.120.2.142

[8] Miti, G. (1973) Temperament of the Child and Environmental Influences in Personality Development. Minerva Pediatrica, 25, 1300-1306.

[9] McInerny, T. and Chamberlin, R.W. (1978) Is It Feasible to Identify Infants Who Are at Risk for Later Behavioral Problems? The Carey Temperament Questionnaire as a Prognostic Tool. Clinical Pediatrics, 17, 233-238. http://dx.doi.org/10.1177/000992287801700305

[10] Cameron, J.R. (1978) Parental Treatment, Children's Temperament, and the Risk of Childhood Behavioural Problems: 2. Initial Temperament, Parental Attitudes, and the Incidence and Form of Behavioral Problems. American Journal of Orthopsychiatry, 48, 140-147. http://dx.doi.org/10.1111/j.1939-0025.1978.tb01295.x

[11] Malhotra, S. and Randhawa, A. (1982) A Schedule for Measuring Temperament in Children. Preliminary Date on Developement and Standardization. Indian Journal of clinical psychology, 9, 203-210.

[12] Conners, C.K. (1985) The Conners’ Rating Scales. Pro-ED, Austin.

[13] Gunter, K.L. (2007) Emotional Understanding and Social Behavior in School-Age Children. Published Annually by the Department of Psychology University of North Carolina at Charlotte, The Undergraduate Journal of Psychology, 20, 1-7.

[14] Rothbart, M.K. (2000) Temperament in Children. University of Oregon Douglas Derryberry Oregon State University. Presented as a State of the Art Lecture at the 26th International Congress of Psychology, Stockholm, 1-9. www.bowdoin.edu/ sputnam/rothbart-temperament-questionnaires/cv/publications/pdf/2002_temp_\%20in_children_r othbart-derryberry.pdf

[15] Foley, M.A., McClowry, S.G. and Castellanos, F.X. (2008) The Relationship between Attention Deficit Hyperactivity Disorder and Child Temperament. Journal of Applied Developmental Psychology, 29, 157-169. http://dx.doi.org/10.1016/j.appdev.2007.12.005

[16] Harris, J.R. Socialization, Personality Development, and the Child's Environments. http://www.thelizlibrary.org/liz/harris.htm

[17] Lonigan, C.J., Vasey, M.W., Phillips, B.M. and Hazen, R.A. (2004) Temperament, Anxiety, and the Processing of Threat-Relevant Stimuli. Journal of Clinical Child \& Adolescent Psychology, 33, 8-20. http://dx.doi.org/10.1207/S15374424JCCP3301_2 